\title{
B-mode ultrasonography of mammary glands of cows, goats and sheep during $\alpha$ - and $\beta$-adrenergic agonist and oxytocin administration
}

\author{
BY RUPERT M. BRUCKMAIER AND JÜRG W. BLUM \\ Institut für Tierzucht, Universität Bern, CH-3012 Bern, Schweiz
}

(Received 30 July 1991 and accepted for publication 28 October 1991)

Summary. Teat and gland cistern of the mammary glands of five dairy cows, five goats and five sheep were scanned in a water bath during $\alpha$-and $\beta$-adrenergic agonist and oxytocin administration. A $5 \mathrm{MHz}$ linear array scanner was used to create vertical cut pictures with the scan plane longitudinally through the teat channel. The i.v. injection of the $\alpha$-adrenergic agonist phenylephrine $(30 \mu \mathrm{g} / \mathrm{kg})$ induced diminution of the section area through teat and gland cistern by $38 \pm 17 \%$ on average within $1 \mathrm{~min}$ in all three species. In contrast, the i.v. injection of the $\beta$ adrenergic agonist isoproterenol $(1 \mu \mathrm{g} / \mathrm{kg})$ did not change the cisternal areas. The i.v. injection of oxytocin $\left(2.0 \times 10^{-3} \mathrm{i} . \mathrm{u} . / \mathrm{kg}\right)$ elicited an enlargement of teat and gland cistern area by $48 \pm 12 \%$ on average. Ultrasonography proved to be a valuable system for visualizing changes of the cisternal volume. Smooth muscle contractions in response to phenylephrine administration are thought to cause area reduction, whereas an expected smooth muscle relaxation after injection of isoproterenol could not be observed by ultrasonography. Milk ejection as induced by oxytocin administration caused dramatic enlargement of the cistern area in all three species.

B-mode ( $\mathrm{B}=$ brightness) ultrasonography creates cross sections of body tissues based on the intensity of high frequency sound reflection. Different reflection intensities are reproduced in different degrees of brightness, i.e. in different tones of grey on the screen. The intensity of sound reflection depends on the degree of variation in acoustic impedance of adjacent structures within a certain tissue. Thus, the nonhomogeneous tissues appear in tones of grey, whereas homogeneous liquids are totally anechoic and therefore appear black on the ultrasound image. Therefore, B-mode ultrasonography would be expected to be a very suitable method for portraying liquid cavities in all kinds of tissues, including mammary gland cisternal cavities of dairy cows, goats and sheep. Only a few investigations with ultrasound on mammary glands of livestock have been performed to our knowledge, and in these studies mostly only the teat area of dairy cows was portrayed (Cartee et al. 1986; Worstorff et al. 1986).

Alveolar milk ejection by oxytocin (OT) released in response to teat stimulation was demonstrated in dairy cows (Schams et al. 1984; Gorewit \& Gassman, 1985; Mayer et al. 1991) and goats (Mosdøl et al. 1981). In sheep, OT release was shown in response to suckling (Fuchs et al. 1987), whereas a milk-ejecting effect in response to hand or machine stimulation has not been regularly identified (Labussière, 1988). Milk ejection in cows and goats increases the intramammary pressure within the teat 
cistern (Mosdøl et al. 1981; Mayer et al. 1991 ; Bruckmaier et al. 1991, and our unpublished observations). In dairy cows, smooth muscles in teat walls and sphincter are sympathetically innervated (Bernabé \& Peeters, 1980). Teat muscle tone is controlled by the sympathoadrenal system (Lefcourt $1982 a, b$ ), mediated by $\alpha$-and $\beta$-adrenergic receptors (Peeters \& de Bruycker, 1975; Bernabé \& Peeters, 1980; Roets \& Peeters, 1985, 1986; Roets et al. 1985). Stimulation of $\alpha$-adrenergic receptors causes teat muscle contraction, whereas $\beta$-adrenergic receptor stimulation induces relaxation (Peeters et al. 1973). Administration of the $\alpha$-adrenergic agonist phenylephrine reduces milk flow and milk yield (Blum et al. 1989). Intramammary pressure does not increase when phenylephrine is administered before teat stimulation, indicating inhibition of milk ejection, and administration of phenylephrine after milk ejection even caused a decrease of intramammary pressure (Bruckmaier et al. 1991). In contrast, the administration of $\beta$-adrenergic agonists enhances milk flow (Hamann, 1981; Blum et al. 1989), but does not influence intramammary pressure (Bruckmaier et al. 1991).

The goal of this study was to develop a suitable method to picture gland and teat mammary cisterns of cows, goats and sheep by B-mode ultrasound and to study effects of exogenous OT and $\alpha$-and $\beta$-adrenergic agonists on the cavities of teat and gland cistern to better explain mechanisms of enhancing or inhibiting effects of OT and $\alpha$-and $\beta$-adrenergic agonists on milk ejection and milk removal.

\section{MATERIALS AND METHODS}

\section{Generation of images}

For correct probe application, the presence of air between probe and the tissue examined must be avoided. The problem is usually solved in ultrasound examinations by using contact jelly, applying the probe directly to the animal's body tissue. For examination of mammary glands, this method is partly practicable for the gland body, but not for picturing soft teats and the connection between teat and gland tissue. Pressing the ultrasound probe to the tissue leads to teat image deformations. As the connection between teat and gland is angular, an application of the probe that simultaneously excludes air and prevents teat image deformations is impossible, even using contact jelly. As a practicable alternative to the direct probe application, immersion of teats and whole glands in a water bath proved to be very successful.

Goats and sheep were made to stand in a plastic tank which was filled with warm $\left(34-36{ }^{\circ} \mathrm{C}\right)$ water to the level of their ventral abdomen, thereby completely covering the mammary gland with water. Then the ultrasound probe was held directly in the water bath without touching the animal. For ultrasonography of dairy cows, two methods were practised. In method 1 the udder was placed in a special plastic bucket of roughly equivalent size and this was slung from the cow's back by a harness. The total weight of the filled bucket was $10-15 \mathrm{~kg}$ and it was easily supported by the animal. The probe was applied to the bucket's wall from the outside using contact jelly. In method 2 the cow was fixed in a restraint box with safety slings supporting her abdomen with one hind leg moved to the back and fixed tightly. The whole udder was immersed in a $40 \times 60 \mathrm{~cm}$ bucket of water and the probe held directly in the water. With method 2 , the quality of the pictures was slightly better than with method 1 because the plastic wall of the bucket weakened and diffused the echo signals.

For ultrasound application on mammary glands, water proved to be an ideal 
transmission medium. Because interfaces between water and air are highly reflective, the use of degassed water is very important for an acceptable picture quality. To this end, a storage tank was filled with water at about $80^{\circ} \mathrm{C}$ several hours before the experiment and allowed to degas and cool to body temperature. Use of fresh water from the mains led to interfering 'snow' on the ultrasound image.

After testing several linear and sector transducers, a $5-\mathrm{MHz}$ linear array scanner (Toshiba PLB-508M, Toshiba Medical Instruments, Tokyo, Japan) proved to be very suitable with respect to range and image resolution for our purposes. This probe creates a cross sectional image as long as $9 \mathrm{~cm}$ and allows a penetration of up to $18 \mathrm{~cm}$ into mammary tissue. On the screen, two of these pictures can be put side by side so that $18 \times 18 \mathrm{~cm}$ scans could be created.

In all three species the scan plane was vertical with the axis longitudinally through the teat canal. For practical reasons, the probe was applied laterally to each quarter in cows, caudally in goats and laterally or ventrally in sheep. Keeping the longitudinal teat channel as scan axis, the probe was swung back and forth to find the cross section with the biggest cavity areas.

Experimental procedures were continuously recorded on video tape and accompanied by a commentary via a microphone. Significant pictures could be printed on paper during review of video tapes. Thermoprints or Polaroid ${ }^{\mathbf{R}}$ copies were made to allow calculation of the areas of the cavities and comparisons between different times. The milk-filled cisternal cavities appeared as black areas on ultrasound pictures. The areas were measured by a digitizing tablet combined with a special computer program (Sigma-Scan ${ }^{\mathbf{R}}, 1988$ ).

\section{Experimental procedures}

Each of five lactating goats (Swiss Saanen, daily milk yield $3.5 \pm 0.3 \mathrm{~kg}$ ), five dairy sheep (East Friesian, daily milk yield $3 \cdot 2 \pm 0.3 \mathrm{~kg}$ ) and five dairy cows (Simmental $\times$ Red Holstein, daily milk yield $26 \pm 2 \mathrm{~kg}$ ) in the middle of their first to fourth lactation were injected i.v. with $30 \mu \mathrm{g} / \mathrm{kg}$ body weight (BW) of the $\alpha$-adrenergic agonist phenylephrine-HCl (Sigma Chemical Co, St Louis, MO 63178, USA), $1.0 \mu \mathrm{g} / \mathrm{kg} \mathrm{BW}$ of the $\beta$-adrenergic agonist isoproterenol-HCl (Sigma) and $2.0 \times 10^{-3}$ i.u. $/ \mathrm{kg} \mathrm{BW}$ of synthetic oxytocin (Vetox ${ }^{\mathrm{R}}$, VMG, Bad Oldesloe, Germany) on different experimental days at 14.30 , i.e. $7-8 \mathrm{~h}$ after the preceding morning milking. For technical reasons it was not possible to use the same animals for all three treatments. To avoid disturbing the animals during experiments, drugs were injected via a catheter into the jugular vein.

After animals or mammary glands had been placed in the water bath (as described above) and after a period of adaptation (5-10 min), sonographic examination was started. For goats and sheep one half, and for cows one quarter of the udder was evaluated in each experiment; however, the udders of sheep, because of their small size, could be pictured as a whole on one ultrasound image. While recording on video tape, a frozen picture of the whole teat and gland cistern area was created. Afterwards the drugs were injected while picturing of the cistern cavities continued. At $3 \mathrm{~min}$ after injection, another frozen picture of the whole teat and gland cistern area was created. For calculation and statistical evaluation of drug effects, cisternal areas, divided into teat and gland areas, were measured on the frozen pictures. 
Table 1. Effects of phenylephrine and oxytocin on teat and gland cistern areas of goats, sheep and cows

\begin{tabular}{|c|c|c|c|c|c|c|c|c|}
\hline \multirow[b]{2}{*}{ Species } & \multirow[b]{2}{*}{$n$} & \multirow[b]{2}{*}{ Treatment } & \multicolumn{3}{|c|}{ Teat cistern area, $\mathrm{cm}^{2}$} & \multicolumn{3}{|c|}{ Gland cistern area, $\mathrm{cm}^{2}$} \\
\hline & & & $\begin{array}{c}\text { Before } \\
\text { treatment }\end{array}$ & $\begin{array}{c}\text { After } \\
\text { treatment }\end{array}$ & $\begin{array}{c}\text { Difference, } \\
\%\end{array}$ & $\begin{array}{c}\text { Before } \\
\text { treatment }\end{array}$ & $\begin{array}{c}\text { After } \\
\text { treatment }\end{array}$ & $\begin{array}{c}\text { Difference, } \\
\%\end{array}$ \\
\hline Goat & 5 & Phenylephrine & $5 \cdot 3 \pm 0 \cdot 8$ & $2.4 \pm 0.5$ & $-55^{*}$ & $17 \cdot 1 \pm 3 \cdot 0$ & $11 \cdot 3 \pm 1 \cdot 6$ & $-34^{*}$ \\
\hline Sheep & 5 & Phenylephrine & $2 \cdot 1 \pm 0 \cdot 1$ & $1 \cdot 1 \pm 0 \cdot 2$ & $-48^{*}$ & $19 \cdot 1 \pm 3 \cdot 4$ & $15 \cdot 0 \pm 3 \cdot 2$ & $-21^{*}$ \\
\hline Cow & 5 & Phenylephrine & $7 \cdot 8 \pm 1.5$ & $3 \cdot 4 \pm 1 \cdot 0$ & $-56^{*}$ & $23 \cdot 3 \pm 6 \cdot 1$ & $189 \pm 6 \cdot 4$ & -19 \\
\hline Goat & 5 & Oxytocin & $7 \cdot 7 \pm 2 \cdot 0$ & $10 \cdot 5 \pm 3 \cdot 4$ & $+36^{*}$ & $15 \cdot 9 \pm 2 \cdot 5$ & $23.4 \pm 6 \cdot 3$ & $+48^{*}$ \\
\hline Sheep & 5 & Oxytocin & $1 \cdot 4 \pm 0.2$ & $2 \cdot 3 \pm 0 \cdot 4$ & $+64^{*}$ & $18 \cdot 8 \pm 2 \cdot 5$ & $30 \cdot 1 \pm 3 \cdot 5$ & $+60^{*}$ \\
\hline Cow & 5 & Oxytocin & $8 \cdot 7 \pm 2 \cdot 1$ & $12 \cdot 1 \pm 2 \cdot 0$ & $+39^{*}$ & $27 \cdot 8 \pm 7 \cdot 2$ & $39 \cdot 3 \pm 8 \cdot 6$ & $+41^{*}$ \\
\hline
\end{tabular}

* Means before and after treatment were significantly different, $P<0.05$.

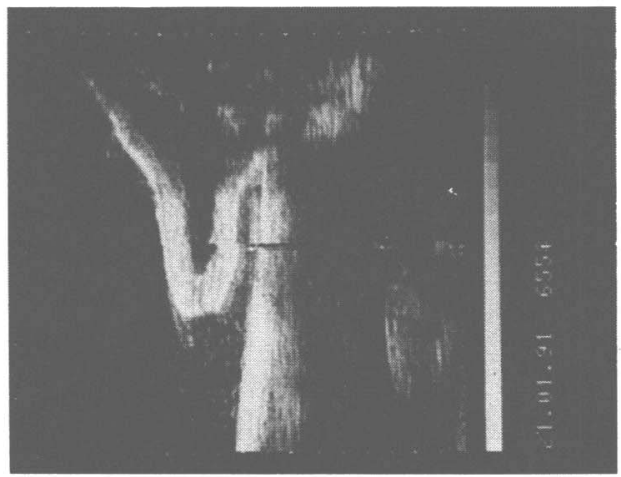

(a)

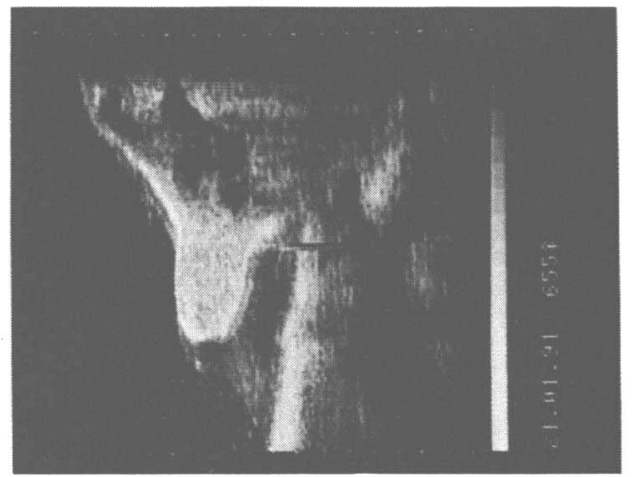

(b)

Fig. 1. Left front quarter of bovine mammary gland (laterally) before $(a)$ and 3 min after (b) i.v. phenylephrine administration.

\section{Statistical analyses}

For statistical evaluations of the results, the SAS program package (SAS 1987, release 6.04) was employed. All values are presented as means \pm sEM. Drug effects were tested for significance $(P<0.05)$ by means of Wilcoxon's two-sample test.

\section{RESULTS}

As shown on Table 1 and on Figs 1-3, injection of the $\alpha$-adrenergic agonist phenylephrine evoked area reduction of teat and gland cisterns in goats, sheep and cows. In cattle, the effect of phenylephrine on the gland cistern area was not statistically significant because there was no apparent change in the gland cistern area for two animals. The response to phenylephrine was visible within 1 min after adminstration. In all three species, the extent of reduction in area was almost double in the teat compared with the gland cistern $(P<0.05)$. In some individuals of each species, phenylephrine administration led to complete disappearance of the teat cistern area on the ultrasound image.

In contrast, the administration of the $\beta$-adrenergic agonist isoproterenol did not change the teat or gland cistern areas in any of the three species within 3 min (not shown).

The administration of OT induced a significant increase in teat and gland cistern 


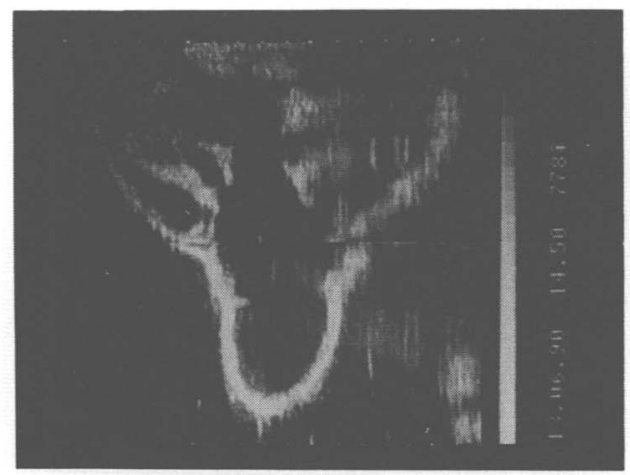

(a)

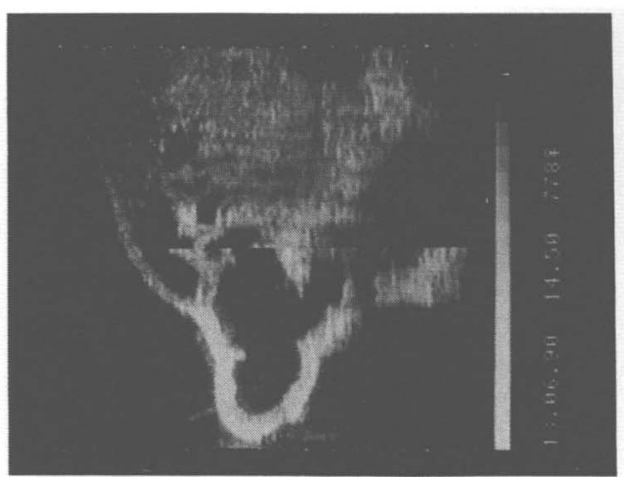

(b)

Fig. 2. Right half of goat mammary gland (caudally) before (a) and 3 min after (b) i.v. phenylephrine administration.

(b)

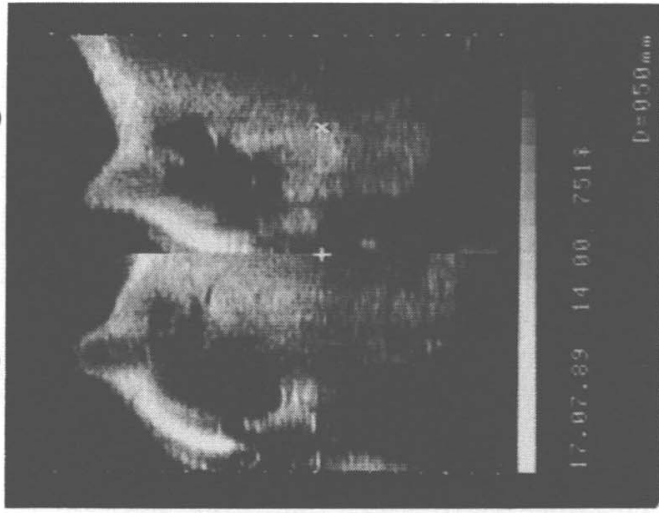

Fig. 3. Sheep mammary gland (laterally) before $(a)$ and 3 min after (b) i.v. phenylephrine administration.

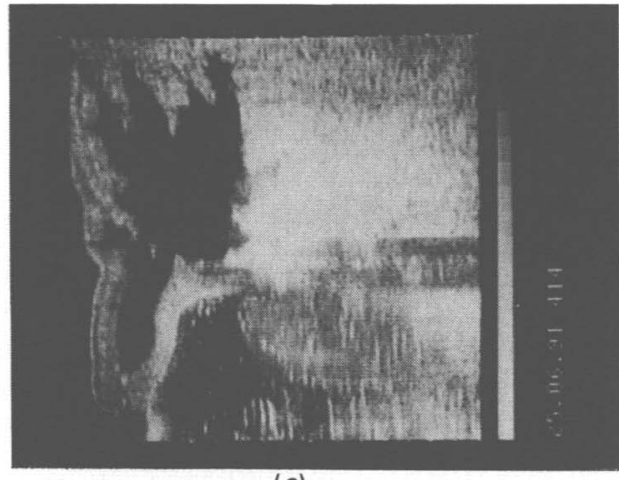

(a)

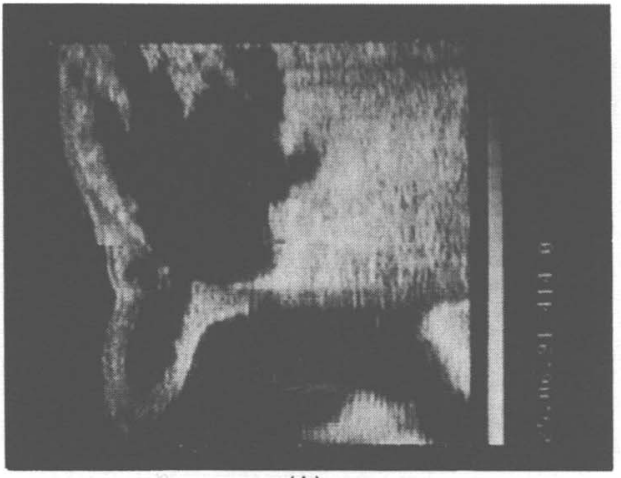

(b)

Fig. 4. Ieft front quarter of bovine mammary gland (laterally) before $(a)$ and $3 \mathrm{~min}$ after (b) i.v. oxytocin administration.

areas in goats, sheep and cows within 1 min (Table 1, Figs 4-6). Area enlargements after $O T$ injection were established after 10-15 s and lasted for another 10-15 s until the maximum areas were reached, accompanied by whirling of grey particles from the edge of tissue into the black gland cistern area. The relative amount of area 


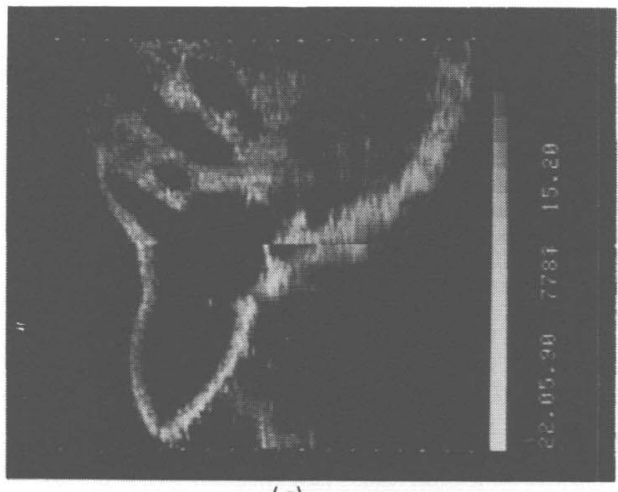

(a)

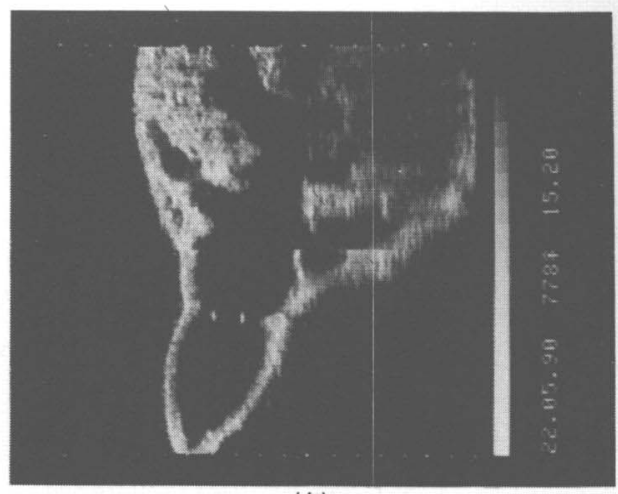

(b)

Fig. 5. Right half of goat mammary gland (caudally) before $(a)$ and 3 min after (b) i.v. oxytocin administration.

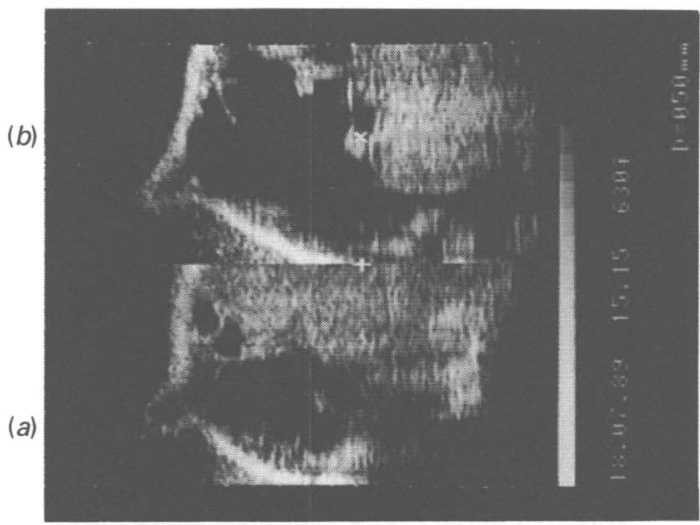

Fig. 6. Sheep mammary gland (laterally) before $(a)$ and 3 min after $(b)$ i.v. oxytocin administration.

increase was bigger in the gland than in the teat cistern in goats, comparable in both cistern parts in sheep and cows.

\section{DISCUSSION}

Ultrasound application in a degassed hand-warm water bath proved to be an excellent method for continuous observation of mammary gland cistern cavities of cows, goats and sheep. Dipping into cold water induced considerable teat contractions (not shown). Obviously, the cistern area obtained by creating cross sectional images through the mammary gland gives good information about the form and volume of the cavities. Investigations on bovine teats have been performed with a similar technique (Cartee et al. 1986; Worstorff et al. 1986). The connection between teat and gland area of the mammary gland could be pictured in natural shape because direct contact of the probe with the tissue was not necessary. As both water and milk stored within the cistern are anechoic media, B-mode ultrasound can be used at a very low gain level with wide working range. To avoid artifacts from sound reflections from the containing vessel, Worstorff el al. (1986) proposed a right-angled vessel for their experiments on teats. As the vessels used in our experiments on whole mammary glands were very large, reflections from the back wall were scarcely 
observed. In contrast, small artifacts were in some cases observed in the region of the angular connection between teat and gland body. Because this area is hyperechoic, a sound 'shadow' appeared on its rear side with a small stripe of reduced brightness on the ultrasound image. The cross section through the maximum cistern area longitudinally through the teat was well defined. As a result, the area variation between repeated measurements at the same time after the preceding milking was $<10 \%$ (not shown).

Images created before drug administration showed considerable differences between the mammary glands of cows, goats and sheep and their cistern cavity systems. Cistern areas of cows and goats were in the same range of size although one udder half of a goat is much smaller than one quarter of a cow's udder. Therefore, in mammary glands of goats a much greater percentage of total milk is stored in cistern cavities (cisternal fraction), whereas most of the milk in bovine udders is stored in gland tissue (alveolar fraction). Ultrasound images of mammary glands of sheep showed clearly that parts of the gland cistern are situated more ventrally than the teats. Obviously, milk in sheep cannot flow entirely by gravity from the gland cistern into the teat cistern. Specific manipulations during milking are required to allow complete milk removal.

\section{Effects of $\alpha$ - and $\beta$-adrenergic agonists}

Reduction of cisternal area in teat and gland cisterns of goats, sheep and cows was observed after phenylephrine administration. This reaction could be expected as $\alpha$-adrenergic receptors were found in bovine smooth muscles of teat tissue (Roets \& Peeters, 1985, 1986) and stimulation of $\alpha$-adrenergic receptors was shown to cause contraction of teat muscles (Peeters et al. 1973). In some individuals, teat muscle contraction caused shrinkage of teat cistern area below the detection limit of the ultrasound, thus explaining the dramatic disturbance of milk removal shown previously (Blum et al. 1989; Bruckmaier et al. 1991). $\alpha$-Adrenergic receptors may also be present in teats of goats and sheep, as similar effects of phenylephrine were found in these species as in cows. Furthermore, area reduction as a response to phenylephrine administration in this study also appeared in the gland part of the cistern, indicating that $\alpha$-adrenergic receptors, besides being in teats, are also present in other parts of mammary tissue of goats, sheep and cows.

Administration of the $\beta$-adrenergic agonist isoproterenol did not induce visible changes in the ultrasound image. The presence of $\beta$-adrenergic receptors in bovine teats (Roets et al. 1985) and the enhancing effect of $\beta$-adrenergic agonists on milk flow have already been shown (Hamann, 1981 ; Blum et al. 1989; Bruckmaier et al. 1991). However, there were no changes of intramammary pressure in response to $\beta$-adrenergic agonists (Bruckmaier et al. 1991). Therefore, the absence of changes in cistern area or volume is not surprising. Obviously, relaxation of the teat smooth muscle tone, induced by $\beta$-adrenergic agonists (Bernabé $\&$ Peeters, 1980), is not accompanied by anatomical changes observable on the ultrasound image.

\section{Effects of oxytocin}

The injection of $2 \cdot 0 \times 10^{-3} \mathrm{i} . \mathrm{u} . \mathrm{OT} / \mathrm{kg} \mathrm{BW}$ has been shown to raise peripheral concentrations of OT corresponding with the range during milking in cows (R. M. Bruckmaier, unpublished results). Injection induced spontaneous area enlargement, i.e. volume enlargement of the cavities of teat and gland cisterns of cows, goats and sheep. The alveolar milk-ejecting effect of OT in cows and goats was shown previously (Schams et al. 1984; Gorewit \& Gassman, 1985; Mosdøl et al. 1981). When 
myoepithelial cells around alveolar cells contract, thus shifting alveolar milk from the gland tissue into the gland cistern, an increase of intramammary pressure in the teat cistern can be detected (Mayer et al. 1991 ; Bruckmaier et al. 1991). Our results show that the pressure increase apparently occurs simultaneously with enlargement of the cistern volume. Whirling effects on the ultrasound image during alveolar milk ejection may be caused by turbulences of unhomogeneous fat particles in the alveolar milk. While undisturbed milk within the cistern is anechoic, echoic capacity and simultaneously sound damping is obviously increased if milk particles are moved. The volume increase, together with whirling effects of ejected alveolar milk, shows the existence of milk ejection as a response to increased oxytocin concentration not only in cows and goats, but also in sheep.

In conclusion, B-mode ultrasonography in a water bath was found to be a very suitable method for picturing mammary cisternal cavities of cows, goats and sheep. In particular, rapid changes of cistern volume, such as that caused by $\alpha$-adrenergic agonists or OT, could be clearly observed.

This study has in part been financed by a special grant of the Eidgenössische Forschungsanstalt für Milchwirtschaft, Liebefeld, and we thank Professor Dr M. Schällibaum for supporting this project. The animals were kindly provided by the Eidgenössische Forschungsanstalt für viehwirtschaftliche Produktion, Grangeneuve (cows, goats) and by the Eidgenössische Technische Hochschule, Zürich (sheep). We thank Dr H. P. Meier, Tierspital Bern, for valuable discussion and help.

\section{REFERENCES}

Bernabé, J. \& Peeters, G. 1980 Studies on the motility of smooth muscles of the teats in lactating cows. Journal of Dairy Research 47 259-275

Blum, J. W., Schams, D. \& Bruckmaier, R. 1989 Catecholamines, oxytocin and milk removal in dairy cows. Journal of Dairy Research 56 167-177

Bruckmaier, R., Mayer, H. \& Schams, D. 1991 Effects of $\alpha$-and $\beta$-adrenergic agonists on intramammary pressure and milk flow in dairy cows. Journal of Dairy Research 58 411-419

Cartee, R. E., Ibrahim, A. K. \& McLeary, D. 1986 B-mode ultrasonography of the bovine udder and teat. Journal of the American Veterinary Medical Association 188 1284-1287

Fuchs, A.-R., Ayromlooi, J. \& Rasmussen, A. B. 1987 Oxytocin response to conditioned and nonconditioned stimuli in lactating ewes. Biology of Reproduction $37301-305$

Gorewit, R. C. \& Gassman, K. B. 1985 Effects of duration of udder stimulation on milking dynamics and oxytocin release. Journal of Dairy Science 68 1813-1818

Hamans, J. 1981 [The influence of a $\beta_{2}$-mimetic substance (Planipart) on the milking behaviour of cows.] Tierärztliche Umschau 36 287-290

LABUSSİ̀re, J. 1988 Review of physiological and anatomical factors influencing the milking ability of ewes and the organization of milking. Livestock Production Science 18 253-274

LefcourT, A. M. 1982 a Effect of teat stimulation on sympathetic tone in bovine mammary gland. Journal of Dairy Science 65 2317-2322

LefcourT, A. M. $1982 b$ Rhythmic contractions of the teat sphincter in bovines: an expulsion mechanism. American Journal of Physiology 242 R181-R184

Mayer, H., Bruckmaier, R. \& SCHams, D. 1991 Lactational changes in oxytocin release, intramammary pressure and milking characteristics in dairy cows. Journal of Dairy Research 58 159-169

Mospøl, G., SjaAstad, 0. V. \& Blom, A. K. 1981 Plasma concentrations of oxytocin and intramammary pressure in goats during manual stimulation of the udder and hand-milking. Journal of Endocrinology 90 159-166

Peeters, G. \& de Bruycker, R. 1975 Influence of sympathomimetic drugs on the motility of bovine teat muscles. Journal of Dairy Research 42 11-19

Peeters, G., de Bruycker, R., Quintelier, W. \& de Paepe, M. 1973 Contractions of teat muscles of lactating cows. Acta Endocrinologica Suppl. 17750

Roets, E. \& Peeters, G. 1985 Identification and characterization of ${ }^{3} \mathrm{H}$-Prazosin binding to $\alpha_{1}$-adrenoceptors in bovine teat muscles. Archives Internationales de Pharmacodynamie et de Thérapie 175 189-198

RoETs, E. \& PeEters, G. 1986 A comparison of the binding characteristics of the $\alpha_{2}$-adrenoceptor antagonists ${ }^{3} \mathrm{H}$-yohimbine and ${ }^{3} \mathrm{H}$-rauwolscine in bovine teat muscles. Archives Internationales de Pharmacodynamie et de Thérapie 279 212-222 
Roets, E., Vauquelin, G., Peeters, G. \& Braeckman, R. 1985 Homogeneity of $\beta$-adrenoceptors on bovine teat muscles. Archives Internationales de Pharmacodynamie et de Thérapie 276 44-49

SAS 1987 SAS User's Guide: Statistics. Cary, NC: SAS Institute

Schams, D., Mayer, H., Prokopp, A. \& WorstorfF, H. 1984 Oxytocin secretion during milking in dairy cows with regard to the variation and importance of a threshold level for milk removal. Journal of Endocrinology $102337-343$

Sigmascan 1988 Corte Madera, CA : Jandel Scientific

Worstorff, H., Steib, J. D., Prediger, A. \& Schmidt, W. L. 1986 [Evaluation of sectional views by ultrasonics for measuring teat tissue changes during milking of cows.] Milchwissenschaft 41 12-15 